\title{
Effect of Video Assisted Teaching Regarding Normal labour on Anxiety among Primi Parturient Mothers
}

\author{
Zeinab Mahmoud Amin ${ }^{1}$, Amal Mohamed Gamal', Samah Mohamed EL \\ Homosy $^{2}$ \\ ${ }^{1}$ B.Sc. Nursing Science, ${ }^{2}$ Assistant professor of maternal and Newborn Health Nursing, \\ Faculty of Nursing, Menoufia University.
}

\begin{abstract}
Labour is an event that had a great psychological, social and emotional meaning for the mother and her family. Fear, stress and anxiety all have marked effects on labor progression and fetus, so mothers need education and support to alleviate anxiety. The study investigates the effect of video assisted teaching regarding normal labour on anxiety among primi parturient women. The study was conducted at El-Shohada $\mathrm{MCH}$ center. The research design was quasi-experimental. The sample size for the study was 50 primi parturient women. 25 of them were assigned to the study group and 25 to the control group. Using Zung self -rating scale as an instrument. The results showed that, there was a highly statistically significant difference between the study and the control groups only at the posttest level of anxiety where $p>0.001$.It is concluded that video assisted teaching was effective in reducing the anxiety of the primi parturient women in study group. It is recommended that video assisted teaching regarding normal labour should be a basic component of the antenatal care programs me for primi parturient women at $\mathrm{MCH}$ centers.

Keywords: normal labour, anxiety, video assisted teaching .
\end{abstract}

\section{Introduction:}

Pregnancy and child birth is one of the greatest events in the life of a woman which she aspires and longs for with great expectation. She has fantasies about pregnancy and motherhood, but when confronted with reality, many of them doubt their ability to cope with this great event. Child birth is a natural and universal phenomenon. Yet, the knowledge of it among average women is haphazard, incomplete or distorted (Brown, 2015).

The stress and anxiety levels increase in the third trimester of pregnancy as the delivery time approaches. so that $90 \%$ of stress and anxiety during pregnancy is related to the process of delivery (Adam, 2012). As a result of fear and anxiety, secretion of stress hormones increase this can lead to preterm birth, lack of progress, low birth weight of the child, and fetal hypoxia (Boakye, 2015). So that, women's access to all health services, along with increased awareness through education during pregnancy and childbirth is critically effective factors in the prevention of mortality and complications in this stage. Promotion of prenatal knowledge and skill prepares mothers for delivery and enhance their health (Bryanton, 2014). (Nabb, 2016) states that video can give essential extra benefits for women learning experiences;

enrich the women's experience about normal labour, improve their cross cultural understanding, develop their creativity, and increase their motivation in learning. .

Learning through video have a long lasting impression as it compels and holds the attention of the viewer. The individual watching the video imitates the behavior and try to be competent in performing it. . They show settings and situations that no amount of discussion can convey. Video, as an educational intervention, is useful because the technology provides multi-media multi- 


\section{Effect of Video Assisted Teaching Regarding Normal labour on Anxiety among Primi Parturient Mothers}

sensory information about complex behavior (Shih, 2016).

When mother watches a movie or TV program, superficial and deep feelings and emotions are elicited, such as excitement, anger, even laughter, relaxation, love, whimsy, or even boredom. These emotions are often triggered or heightened by the mood created by specific visual scenes, the actors, and/or the background music. A video can have a strong effect on mind and senses (Hosseinasab, 2015). So this research use video regarding normal labour to study its effect in reducing anxiety of primiparous before occurrence of labour in order to ensure safe labour.

\section{Significance of the study}

High levels of anxiety during pregnancy regarding labour have worldwide effect on mankind. Inappropriate mental and physical preparation can increase their anxiety (El zanaty, 2015).It causes change in steroid genes, destruction of social behavior and fertility rate in adulthood. Also, anxiety during pregnancy is accompanied by emotional problems, hyperactivity disorder, decentralization and disturbance in cognitive development of children (Simon, 2014) Therefore, this study was conducted to investigate the effect of video assisted teaching regarding normal labour on anxiety among primi parous women

\section{Aim of the study}

This study was conducted to investigate the effect of video assisted teaching regarding normal labour on anxiety among primi parous Women.

\section{Research Hypothesis}

1. 1-Primi parous women who receive video assisted teaching regarding normal labour have a lower level of anxiety than those who do not watch that video and receive routine care.

2. 2-Primi parous women who receive video assisted teaching regarding normal labour have ahigher knowledge level than those who do not watch that video and receive routine care

\section{Method}

\section{Design:}

The quasi experimental design (Nonequivalent groups pretest (posttest) design was utilized in this study.

\section{Setting:}

The present study was conducted at maternal and child health center in ElShohada center, which provides many services to public clients and care for women during pregnancy and family planning services, dental clinic, medical clinic, sterilization unit and provides many services to children such as immunizations.

\section{Sampling:}

A purposive sample of 50 Primi parturient women were selected randomly and divided alternatively into two equal groups (study group and control group).

\section{The Inclusion Criterion was:}

Primi parturient women who were in the third trimester.

\section{The exclusion Criteria were:}

AHigh risk pregnant women such as preterm rupture of membranes, pregnancy induced hypertension and gestational diabetes mellitus, because these risks produce more stress.

\section{Sample size calculation}

Population rate annually is 740 primi parous women at health center in Shohada. 


\section{Effect of Video Assisted Teaching Regarding Normal labour on Anxiety among Primi Parturient Mothers}

Sample size

was calculated at power80\% and confidence level $95 \%$ using the following equation:n $=(Z \alpha / 2+Z \beta) 2^{*}$ $2 * \sigma 2 / \mathrm{d} 2$

$\mathrm{Z} \alpha / 2$ is the critical value of the normal distribution at $\alpha / 2$ (e.g for a confidence level of $95 \%, \alpha$ is 0.05 and the critical value is 1.96). $Z \beta$ is the critical value of the normal distribution at $\beta$ (e.g for a power of $80 \%, \beta$ is 0.2 and the critical value is 0.84$). \sigma 2$ is the population variance, and $d$ is the difference one would like to detect. The calculated sample was 42 participants increased by $10 \%$ to avoid dropouts so the sample increases to 50 divided into two groups 25 inthe study group and 25 in the control group.

\section{Tools}

Throughout the course of the present study data were collected using the following tools:

\section{Tool 1:}

knowledge of women structured in an interview questionnaires: designed by the researcher and was submitted to validity and reliability tests.

\section{It included the following parts:}

- Part1: socio demographic characteristics (age, address, occupation, education and husband level of education and income).

- Part2: obstetrical data: such as gestational age, gravity

- Part3: knowledge assessment: it consisted of knowledge about definition of normal labour, stages of normal labour, measures used to relieve pain during labour.

\section{Scoring:}

- Scoring system for each item

\begin{tabular}{|l|l|}
\hline Yes & - 2 \\
\hline No & - 1 \\
\hline
\end{tabular}

Total knowledge score ranged from 6 to 12

\begin{tabular}{|l|c|}
\hline poor knowledge & $6-9(<50 \%)$ \\
\hline good knowledge & $10-12(>50 \%)$ \\
\hline
\end{tabular}

\section{Validity of tool 1:}

The tool was developed by the researcher after the review of literature. The tool and tested for its content validity by five qualified experts (three experts from Faculty of Nursing and two physicians from obstetrics and gynecology department at Faculty of Medicine) and modifications were made and incorporated into the tool before pilot study.

\section{Reliability}

Test-retest reliability was used the researcher for testing the internal consistency of the instrument. It was done by the administration of the same instrument participants under similar conditions on two or more occasion. Scores from repeated testing were compared to test the consistency of the results over time.

\section{Tool 2:}

The Zung Self-Rating Anxiety Scale (SAS). It was adopted from William (2019).

SAS is a 20-item self-report assessment scale. It was used to measure anxiety levels, based on scoring in 4 groups of manifestations: (cognitive, autonomic, motor and central nervous system symptoms). For answering the statements the participants should indicate how much each statement applies to her within a period of one or two weeks prior to taking the test. Each question is scored on a Likert-type scale of 1-4 (based on these replies: "a little of the time," "some of the time," "a good part of the time," "most of the time"). Some questions are negatively worded to avoid the problem of set 


\section{Effect of Video Assisted Teaching Regarding Normal labour on Anxiety among Primi Parturient Mothers}

response. Overall assessment is done by total score.

\section{The scores were interpreted as follows:•}

- Normal Range (25\%-55\%).

- Mild to Moderate Anxiety Levels (56\%-74\%).

- Marked to (75\%-92\%).

- Severe Anxiety Levels (93\%-).

- Extreme Anxiety Level (100\%).

\section{Validity and reliability of SAS}

The validity of (SAS), prepared by Zung, has been widely used in research and in clinical practice for discovering anxiety. The total SAS score can vary from 20 (no anxiety at all) to 80 (severe anxiety). The following parameters were calculated: (a) internal consistency of the SAS providing that Cronbach's $\alpha$ co-efficient, (b) its testretest reliability in terms of Intra class Correlation Coefficient (ICC) and (c) it was collaborative and convergent validities via its score's Spearman's rho correlations with both the state and trait subscales of STAI-Gr X and the ZDRS. Moreover, in order to assess SAS' discriminant validity, the scale's scores of the three groups of participants (psychiatric patients, physically ill and general population individuals) were compared among each other, providing that Kruskall Wallis and Mann Whitney U tests. SAS Cronbach's alpha was 0.897 while ICC regarding its testretest reliability equalize was 0.913 . Spearman's rho regarding validity: (a) when SAS is considered STAI-Gr.-X (state), equals it 0.767 , (b) when SAS is consideration STAI-Gr. X (trait), it equals 0.802 and (c) when SAS is compared to ZDRS, it equals 0.835 . Mentally ill scored clearly higher in SAS compared to both the healthy and the general population. Finally, the SAS Greek version renders very satisfactory psychometric properties concerning its reliability

\section{Ethical considerations}

The approval of ethical research committee, Faculty of Nursing Menoufia University was obtained. Approaches to ensuring the ethical issues were considered in the study regarding confidentiality and informed consent. A formal written acceptance was obtained from each participant.

An official letter was taken from the dean of the faculty of nursing, Menoufia University and was submitted to the directors of the study settings to carry out the study .An official permission was obtained to carry out the study from the directors of the above mentioned.

\section{Piloting the tool}

Piloting was conducted to test the feasibility, applicability, clarity and understandability of the instrument .It was conducted on $10 \%$ of the total study participants (five women) .All women who participated in piloting were excluded from the intervention.

\section{Procedure}

.In the beginning the researcher introduced herself to the pregnant women in the study and explained its purpose and nature of the study to obtain their acceptance to be recruited in the study as well as to gain their cooperation.

All participating women were informed that the information they provided during the study would be kept confidential and used only for statistical purpose after finishing the study.

\section{Phases of the study}

The study was carried out in three phases, preparatory phase, 


\section{Effect of Video Assisted Teaching Regarding Normal labour on Anxiety among Primi Parturient Mothers}

implementation phase and evaluation phase

\section{1-Preparatory phase}

An extensive review of past and current literature was done to cover the various aspects of the problem by the use of electronic dissertations, available books, articles and the studies related to the effect of video assisted teaching of normal labour on anxiety.

\section{2-Implementation phase}

- The data collection started in October 2019 and ended in December 2019.

- During the initial visit, the researcher introduced herself to the purposive sample and provided verbal explanation about the purpose and methods of data collection.

- Data was collected one day /week (Monday) between 9am to $12 \mathrm{pm}$. A number of 10-12 women were interviewed daily.

- Each woman took about 8-10 minutes to answer the questionnaire.

- This study included 2 groups (study and control groups) of primi parturient women at the third trimester

- The researcher selected 25 women at first to be the control group. Then she selected other 25 women to be the study group.

- The control group received usual antenatal care at $\mathrm{MCH}$ center and was exposed to all conditions of study group except video assisted teaching

- Each participant assigned to both groups was asked to complete pretest data at first .The researcher recorded the participants "telephone number and address in order to follow up them

- After that the researcher presented the video about normal labour. The

Results duration of video was half an hour and contained information about preparation for labour, definition of normal labour, stages of normal labour, measures used to relieve pain during labour,

- After watching the video, the researcher gave the women the opportunity to express their feelings and ask question.

- After the sessions the (post-test) was given to the study group.

- Follow up step: the researcher follow up mothers by phone after their expected date of delivery to know psychological status during and after labor using SAS.

- Evaluation phase was applied by comparing anxiety score of pre- post and Follow up for the study and control groups. Follow up was done during the days of labour by comparing anxiety level for the study and control groups.

\section{Statistical Analysis:-}

Data were coded and transformed into a specially designed form to be suitable for computer entry process. Data were entered and analyzed by using SPSS (Statistical Package for Social Science) statistical package version 22. Graphics were done using Excel program.

Qualitative data were presented in the form of frequency distribution tables, numbers and percentages. It was analyzed by chi-square $\left(\chi^{2}\right)$ test. However, if an expected value of any cell in the table was less than 5, Fisher Exact test was used( if the table contained cells), or Likelihood Ratio (LR) test (if the table was more than 4 cells). McNamara's test was used to measure the association between paired qualitative data. A statistical significant difference was considered if $\mathrm{p}<.05$. 
Table (1): The socio demographic Characteristics of The Studied Primi Parturient women Pre intervention $(\mathrm{N}=50)$

\begin{tabular}{|c|c|c|c|c|c|c|}
\hline \multirow{3}{*}{$\begin{array}{c}\text { Social } \\
\text { characteristics }\end{array}$} & \multicolumn{4}{|c|}{ Studied groups } & \multirow{3}{*}{$\begin{array}{c}\text { Test of } \\
\text { significant } \\
X^{2}\end{array}$} & \multirow{3}{*}{$P$ value } \\
\hline & \multicolumn{2}{|c|}{$\begin{array}{l}\text { Control } \\
(\mathrm{No}=25)\end{array}$} & \multicolumn{2}{|c|}{$\begin{array}{c}\text { Study gr. } \\
\text { (No=25) }\end{array}$} & & \\
\hline & No. & $\%$ & No. & $\%$ & & \\
\hline \multicolumn{7}{|l|}{ Residence } \\
\hline $\begin{array}{l}\text { Rural } \\
\text { Urban }\end{array}$ & $\begin{array}{c}9 \\
16\end{array}$ & $\begin{array}{l}36 \\
64 \\
\end{array}$ & $\begin{array}{l}11 \\
14\end{array}$ & $\begin{array}{l}44 \\
56 \\
\end{array}$ & 0.000 & $\begin{array}{c}\mathrm{P}=1.0 \\
\mathrm{~ns}\end{array}$ \\
\hline \multicolumn{7}{|l|}{ Age groups } \\
\hline $\begin{array}{c}15-19 \text { years } \\
20-24 \mathrm{Y} \\
25-30 \mathrm{Y} \\
\end{array}$ & $\begin{array}{c}5 \\
19 \\
1 \\
\end{array}$ & $\begin{array}{c}20 \\
76 \\
4 \\
\end{array}$ & $\begin{array}{c}9 \\
13 \\
3 \\
\end{array}$ & $\begin{array}{l}36 \\
52 \\
12 \\
\end{array}$ & 3.6 & $\begin{array}{c}\mathrm{P}=0.06 \\
\mathrm{~ns}\end{array}$ \\
\hline \multicolumn{7}{|l|}{ Marital status: } \\
\hline $\begin{array}{c}\text { Married } \\
\text { Divorced }\end{array}$ & $\begin{array}{c}25 \\
0\end{array}$ & $\begin{array}{c}100 \\
0\end{array}$ & $\begin{array}{c}24 \\
1\end{array}$ & $\begin{array}{c}96 \\
4\end{array}$ & 1.02 & $\begin{array}{c}\mathrm{P}=0.31 \\
\mathrm{~ns}\end{array}$ \\
\hline $\begin{array}{l}\text { Wife Education: } \\
\text { 2ry education } \\
\text { University }\end{array}$ & $\begin{array}{l}15 \\
10 \\
\end{array}$ & $\begin{array}{l}60 \\
40 \\
\end{array}$ & $\begin{array}{l}14 \\
11 \\
\end{array}$ & $\begin{array}{l}56 \\
44 \\
\end{array}$ & 0.32 & $\begin{array}{c}\mathrm{P}=0.56 \\
\mathrm{~ns}\end{array}$ \\
\hline $\begin{array}{l}\text { Mother job: } \\
\text { Working } \\
\text { HW }\end{array}$ & $\begin{array}{c}6 \\
19\end{array}$ & $\begin{array}{l}24 \\
76\end{array}$ & $\begin{array}{c}8 \\
17\end{array}$ & $\begin{array}{l}32 \\
68\end{array}$ & 0.39 & $\begin{array}{c}0.52 \\
\mathrm{~ns}\end{array}$ \\
\hline $\begin{array}{l}\text { Father job: } \\
\text { Employee } \\
\text { Work with pay } \\
\text { Free business } \\
\end{array}$ & $\begin{array}{c}3 \\
8 \\
14 \\
\end{array}$ & $\begin{array}{l}12 \\
32 \\
56 \\
\end{array}$ & $\begin{array}{c}. . \\
5 \\
5 \\
15 \\
\end{array}$ & $\begin{array}{l}20 \\
20 \\
60 \\
\end{array}$ & 1.2 & $0.54 \mathrm{~ns}$ \\
\hline \begin{tabular}{|} 
Father Education: \\
R\&W+ basic \\
2ry education \\
University
\end{tabular} & $\begin{array}{c}3 \\
16 \\
6\end{array}$ & $\begin{array}{l}12 \\
64 \\
24\end{array}$ & $\begin{array}{c}\ddot{4} \\
13 \\
8\end{array}$ & $\begin{array}{l}16 \\
52 \\
32\end{array}$ & 2.2 & $0.53 \mathrm{~ns}$ \\
\hline $\begin{array}{l}\text { Income/month: } \\
\text { Not enough } \\
\text { Enough }\end{array}$ & $\begin{array}{c}0 \\
25\end{array}$ & $\begin{array}{c}0 \\
100\end{array}$ & $\begin{array}{c}5 \\
20\end{array}$ & $\begin{array}{l}20 \\
80\end{array}$ & 5.6 & $0.02 \mathrm{sig}$ \\
\hline Total & 25 & 100 & 25 & 100 & 100 & \\
\hline
\end{tabular}


Table 1 shows that, the majority of primi parturient women were resident of urban areas $56 \%$ and $64 \%$ for study and control groups. $76 \%$ of women in the study group ranged from 20-24 yrs. approximately three quarters $(76 \%)$ of them compared to $52 \%$ in the control group were Housewives, $60 \%$ and $56 \%$ of women in the study and control group received secondary education . No statistical significant differences were found between the social characteristics of primi parous women in the study and control groups at $5 \%$ level of statistical significance .

Table 2: Obstetric Data of Both Study and Control $(\mathrm{N}=50)$

\begin{tabular}{|c|c|c|c|c|c|c|}
\hline \multirow{3}{*}{ Obstetric Data } & \multicolumn{4}{|c|}{ Studied groups } & \multirow{3}{*}{\begin{tabular}{|c|} 
Test of \\
significan \\
$\mathbf{t}$ \\
$\mathbf{X}^{2}$ \\
\end{tabular}} & \multirow[t]{3}{*}{$P$ value } \\
\hline & \multicolumn{2}{|c|}{ Control } & \multicolumn{2}{|c|}{ Cases } & & \\
\hline & No. & $\%$ & No. & $\%$ & & \\
\hline \multicolumn{7}{|l|}{ Duration of marriage } \\
\hline $1-4$ years & 23 & 92 & 23 & 92 & \multirow{2}{*}{$\begin{array}{c}\text { Fisher exact } \\
\text { test }\end{array}$} & \multirow{2}{*}{$\begin{array}{l}\mathrm{P}=0.69 \\
\mathrm{NS}\end{array}$} \\
\hline $5-9 \mathrm{Y}$ & 2 & 8 & 2 & 8 & & \\
\hline \multicolumn{7}{|l|}{ Age of marriage: } \\
\hline $10-14 \mathrm{Y}$ & 12 & 48 & 13 & 52 & \multirow{2}{*}{1.10} & \multirow{2}{*}{$\begin{array}{c}\mathrm{P}=0.50 \\
\mathrm{NS}\end{array}$} \\
\hline $15-19 \mathrm{Y}$ & 13 & 52 & 12 & 48 & & \\
\hline $\begin{array}{l}\text { Duration of menstruation: } \\
3-4 \text { days }\end{array}$ & 10 & 40 & 10 & 40 & \multirow[t]{2}{*}{0.00} & \multirow{2}{*}{$\begin{array}{l}\mathrm{P}=1.0 \\
\mathrm{NS}\end{array}$} \\
\hline 5 - 8 days & 15 & 60 & 15 & 60 & & \\
\hline $\begin{array}{c}\text { Had abortion before } \\
\text { Yes }\end{array}$ & 3 & 12 & 4 & 16 & \multirow[t]{2}{*}{ Fisher } & \multirow[t]{2}{*}{$\begin{array}{l}0.50 \\
\text { NS }\end{array}$} \\
\hline No & 22 & 88 & 21 & 84 & & \\
\hline $\begin{array}{l}\text { If yes, place of follow up: } \\
\text { General hospital }\end{array}$ & 3 & 14.3 & 1 & 5 & \multirow{4}{*}{2.1} & \multirow{4}{*}{$0.35 \mathrm{NS}$} \\
\hline Health unite & 1 & 4.8 & 3 & 15 & & \\
\hline Private clinic & 17 & 80.9 & 16 & 80 & & \\
\hline No follow up & 4 & 16 & 5 & 2 & & \\
\hline
\end{tabular}

Table (2) No significant differences was found between study and control group regarding obstetric profile. 


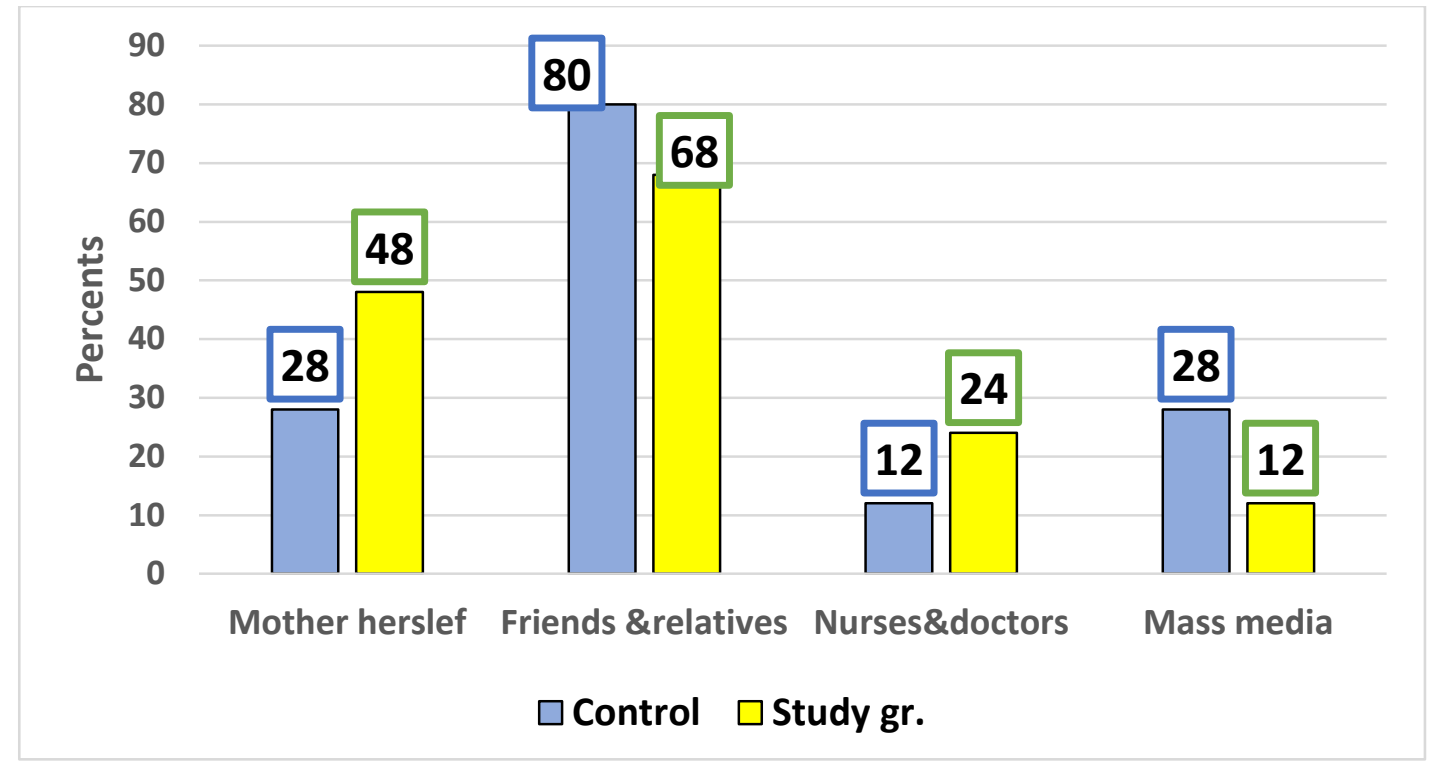

Fig(1): Sources of Knowledge about Normal Labour of Studied women before Intervention

Figure (1) shows that, there were no significant differences between control and the study groups of primi parturient women regarding any source of information about normal labour, $(\mathrm{P}>0.05)$ for each. Unfortunately, the medical team show lower percentages $(12 \% \& 24 \%$ respectively) less than both relatives or friends $(80 \% \& 68 \%)$ respectively and the mother herself read about normal labour $(28 \% \& 48 \%)$ respective

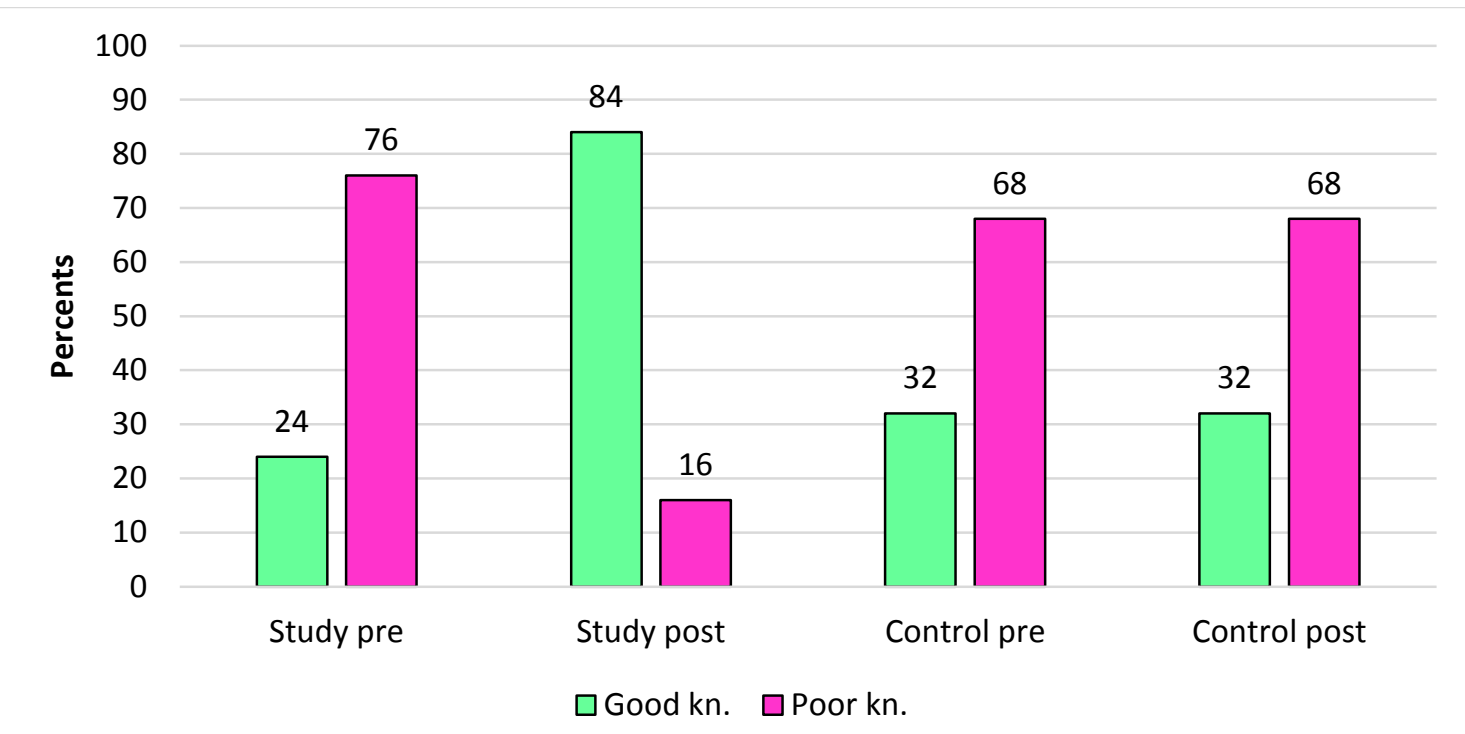

Fig.2: Levels of Total Knowledge Score about Normal labour, among Study and Control Groups Pre and Post Intervention.

Figure (2) illustrates that total knowledge score increased in study group post intervention, the score was 24 pre interventions and was 84 post intervention. In control group poor knowledge of primi parturient women in pre intervention 68 and post intervention 68. 


\section{Effect of Video Assisted Teaching Regarding Normal labour on Anxiety among Primi Parturient Mothers}

Table (3) Anxiety level of the study and Control Group before Intervention $(\mathrm{N}=50)$

\begin{tabular}{|c|c|c|c|c|c|c|c|c|}
\hline \multirow[t]{2}{*}{ Zung Self-Rating Anxiety Scale (SAS) } & \multicolumn{2}{|c|}{$\begin{array}{l}\text { A little of } \\
\text { the time }\end{array}$} & \multirow{2}{*}{$\begin{array}{c}\begin{array}{c}\text { Some of } \\
\text { the time }\end{array} \\
\% \mathrm{C}\end{array}$} & \multicolumn{2}{|c|}{$\begin{array}{c}\text { Good part } \\
\text { of } \\
\text { the time }\end{array}$} & \multicolumn{2}{|c|}{$\begin{array}{l}\text { Most of } \\
\text { the time }\end{array}$} & \multirow[b]{2}{*}{$\mathbf{S \%}$} \\
\hline & $\% \mathrm{C}$ & $\% \mathrm{~S}$ & & $\% \mathrm{~S}$ & $\% \mathrm{C}$ & $\% \mathrm{~S}$ & $\% \mathrm{C}$ & \\
\hline 1 I feel more nervous and anxious than usual. & 0 & 8 & 96 & 92 & 4 & 0 & 0 & 0 \\
\hline 2 I feel afraid for no reason at all. & 4 & 12 & 84 & 76 & 12 & 12 & 0 & 0 \\
\hline 3 I get upset easily or feel panicky. & 4 & 8 & 92 & 76 & 4 & 16 & 4 & 16 \\
\hline 4 I feel like I'm falling apart and going to pieces. & 12 & 40 & 88 & 60 & 0 & 0 & 0 & 0 \\
\hline $\begin{array}{l}5 \text { I feel that everything is all right and nothing bad will } \\
\text { happen. }\end{array}$ & 0 & 8 & 44 & 60 & 56 & 28 & 0 & 4 \\
\hline $6 \mathrm{My}$ arms and legs shake and tremble. & 12 & 36 & 80 & 64 & 8 & 0 & 0 & 0 \\
\hline 7 I am bothered by headaches neck and back pain. & 36 & 44 & 44 & 40 & 20 & 16 & 0 & 0 \\
\hline 8 I feel weak and get tired easily. & 0 & 8 & 40 & 52 & 60 & 36 & 0 & 4 \\
\hline 9 I feel calm and can sit still easily. & 12 & 28 & 48 & 68 & 40 & 4 & 0 & 0 \\
\hline 10 I can feel my heart beating fast. & 4 & 24 & 88 & 64 & 8 & 12 & 0 & 0 \\
\hline 11 I am bothered by dizzy spells. & 36 & 28 & 64 & 68 & 0 & 4 & 0 & 0 \\
\hline 12 I have fainting spells or feel like it. & 28 & 68 & 60 & 28 & 12 & 4 & 0 & 0 \\
\hline 13 I can breathe in and out easily. & 8 & 16 & 60 & 56 & 32 & 28 & 0 & 0 \\
\hline $\begin{array}{l}14 \text { I get feelings of numbness and tingling in my } \\
\text { fingers \& toes. }\end{array}$ & 4 & 8 & 64 & 44 & 32 & 48 & 0 & 0 \\
\hline 15 I am bothered by stomach aches or indigestion. & 0 & 4 & 44 & 36 & 56 & 60 & 0 & 0 \\
\hline 16 I have to empty my bladder often. & 0 & 12 & 64 & 44 & 36 & 44 & 0 & 0 \\
\hline 17 My hands are usually dry and warm. & 16 & 32 & 68 & 60 & 16 & 8 & 0 & 0 \\
\hline 18 My face gets hot and blushes. & 48 & 44 & 48 & 44 & 4 & 12 & 0 & 0 \\
\hline 19 I fall asleep easily and get a good night's rest. & 40 & 48 & 40 & 40 & 20 & 12 & 0 & 0 \\
\hline 20 I have nightmares. & 80 & 80 & 0 & 8 & 20 & 12 & 0 & 0 \\
\hline
\end{tabular}

$\mathrm{C}=$ Control group $\quad \mathrm{S}=$ Study group

Table( 3) revealed that the majority of primi parturient womenfelt more anxious and nervous than usual some of time in study group and control group (96\%-92\% respectively).primi parturient women got upset easily and felt panicky some of time (92\% -76\% respectively) also, they had nightmares in both groups with equal proportion $80 \%$. Primi parturient women felt afraid for no reason at all some of time with proportion (76\%-84\% respectively). This scale demonstrated that primi parturient women suffered from anxiety regarding normal labour ,SO primi parturient women need intervention to ensure good outcome for mother and her baby and avoid complications for them.

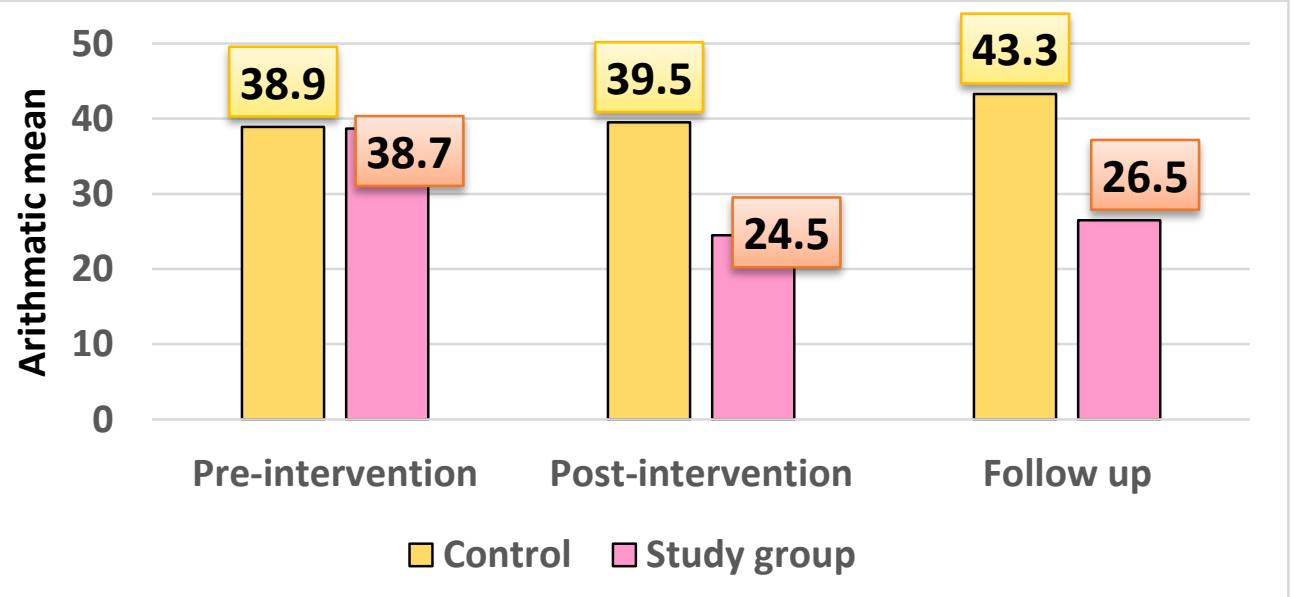




\section{Effect of Video Assisted Teaching Regarding Normal labour on Anxiety among Primi Parturient Mothers}

Fig (3): Comparison of Pre, Post, and Follow up Intervention Mean of Total Score of Anxiety Among Primi Parturient Women in Control and Study Groups.

Figure (3) shows that total mean of anxiety score pre intervention in both control group and study group was (38,9-38,7 respectively), while post intervention was $\quad(39,5-24.5$ respectively).in follow up total mean of anxiety in control group and study group was (43.3-26.5 respectively).

Fig(4)Estimated Anxiety Means of Study group pre, post and follow up Periods

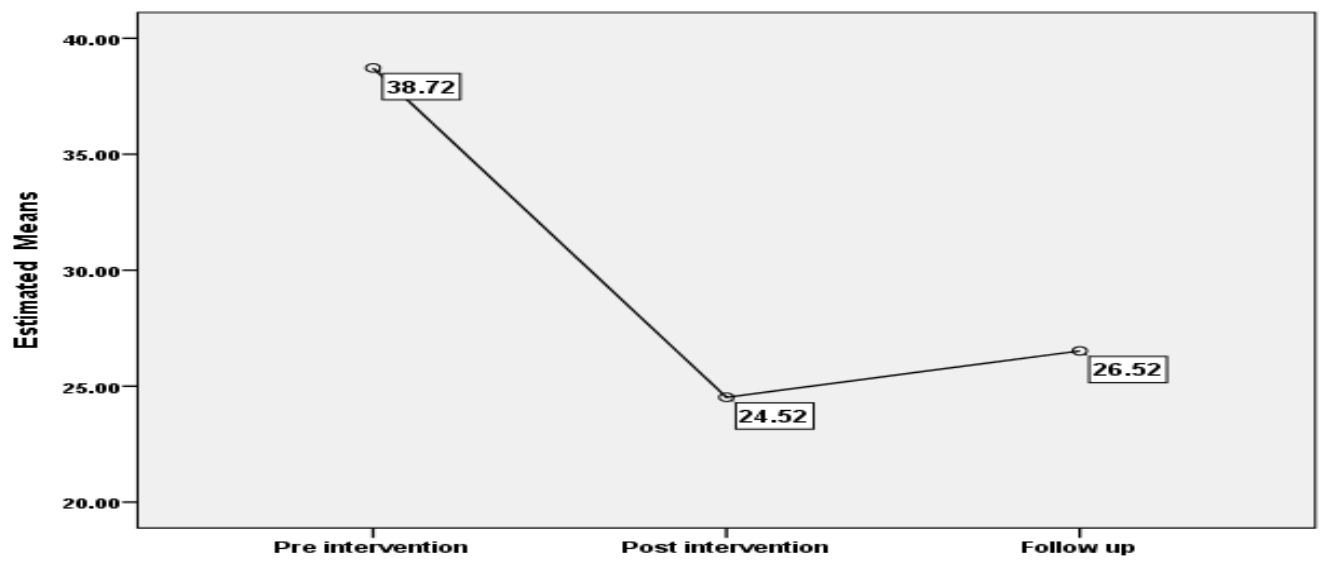

Figure (4) demonstrates that there was a significant decrease in mean anxiety scores over time from pre intervention (38.7) to post intervention (24.5). Although follow up mean anxiety scores was a little bit higher than

\section{Discussion}

Pregnancy and childbirth are a long time journey and it is accompanying with physiological, psychological and emotional changes which may cause positive or negative effect on the woman's life, the baby, and the family (Aune , 2015).

Certain levels of fear and anxiety about childbirth are expected, especially among first -time mothers. However, problems arise when these feelings negatively impact a woman's decisions and perceptions about birth process (Soumya, 2016). (26.5)the post intervention one, but follow up comparisons indicated that each pairwise difference was significant, $\mathrm{P}=0.000$

The current study findings succeeded in clarifying research hypothesis.

As regards socio-demographic and obstetrics data the present study revealed that there were no statistically significant differences between study and control groups regarding the sociodemographic characteristics. This result was very important in minimizing the effects of group differences that could affect outcomes measures. This result comes in agreement with Kaso.M et al (2014) conducted a community based cross sectional study to assess knowledge 


\section{Effect of Video Assisted Teaching Regarding Normal labour on Anxiety among Primi Parturient Mothers}

and practices towards birth preparedness and complication readiness and associated factors among 575 women of reproductive age group (15-49).Preparation for birth and its complication was higher among educated mothers (95\%).ANC visit ( $95 \%$ ), knowledge of obstetric complications ( 95\%) and those who had given birth at health facility before their last delivery

$(95 \%)$ were also significantly associated with birth preparedness and complication readiness. The study identified that community education about preparation for birth and its complication and empowerment of women through expansion of educational opportunities are important steps in improving birth preparedness.

This result comes disagreement with Goli,S et al (2013) conducted a survey to assess the birth preparedness and its effects on place of delivery and postnatal checkups among primi and multi gravid mothers. The researcher found that only $32 \%$ of women have birth preparedness. The women who were well prepared belong to higher age group (45\%), higher education $(35 \%)$ and with

higher women autonomy $(86 \%)$. The conclusion of the survey was that birth preparedness is one of the critical factors in determining the likelihood of having institutional delivery and checkups after delivery.

Regarding level of education the present study revealed that most of women in both groups had high education. This has been very important during the study where the educated women had more understanding and reaction during video assisted teaching. This reaction affected self-confidence and anxiety.

Regarding knowledge about labour and measures to relieve pain and anxiety the current study revealed that before the intervention (video assisted teaching) there was no statistical significant difference between the study and control groups regarding in knowledge score level as the majority of both groups had poor knowledge. However, at post intervention there was highly statistically difference between the study and control groups where the majority of the study group had good knowledge in contrast with the control group who still had poor knowledge.

This results comes in agreement with Gagnon, A.J, Sandall, J .(2010) they conducted a study to assess the effects of antenatal education on knowledge acquisition, anxiety reduction, sense of control, pain control in labor and birth support. The result was that the largest of the included studies examined an educational and social support intervention to increase vaginal birth. This showed that the effects of general antenatal education for childbirth or parenthood, or both, remain positive and improve their knowledge anxiety reduction

Regarding the effect of video assisted teaching on the levels of anxiety the study showed there was a significant decrease in mean anxiety scores over time from pre intervention to post intervention .Although follow up mean anxiety scores was a little bit higher than post intervention one, but follow up comparisons indicated that each pairwise difference was significant, $\mathrm{P}$ $=0.000$.This result leads to the suggestion that participation in the study group had decrease on anxiety about labor, which is in favor of the hypothesis.

there was no change in control group primi parturient mothers' anxiety scale when measured before, post, and follow up intervention. The results indicated a non- statistically significant effect ( of receiving routine management) on mean anxiety scores , Follow up comparisons indicated that 


\section{Effect of Video Assisted Teaching Regarding Normal labour on Anxiety among Primi Parturient Mothers}

each pairwise difference was not significant, for each. Although there were little increases in mean scores of anxiety over time, this increase was not -significant statistically. Thus there is an evidence to accept the null hypothesis. This result may be due to two factors, the short duration of follow up of mothers (only 3 months), and / or small of sample size of primi parturient in the control group. In addition, this result approves this research hypothesis which stated "Prim parturient mothers who will receive video assisted teaching regarding normal labour will have lower level of anxiety than mothers who will not see that video.

These result agreed with Nigai (2012) who conducted a quasi-experimental study on effects of a childbirth education using videos. The study was conducted in two regional public hospitals in Hong Knong that provided routine childbirth education programs with similar content and structure. One hospital was being randomly selected as experimental hospital. A convenience sample of 184 Chinese pregnant women attending the child birth education. The experimental group received the childbirth education using videos. The comparison group received the routine child birth education alone. The result showed that, the childbirth education using videos appears to be a very promising intervention for promoting learned resourcefulness and minimizing the risk of anxiety.

Also, This result agreed with supportive study by Fabian and Roadstead (2011) they investigated first time mothers' views about child birth and parenthood education, in Sweden. The study revealed that child birth education helped majority of first time mothers to prepare for child birth process. The first time mothers felt more relaxed which help them to cope easily with the process of labour. This finding comes in agreement with Sharma, S. et al., (2012 ) they conducted an experimental study to see the effect of psycho-educational program through video teaching related to labor and delivery on primi gravitas' level of anxiety during their third trimester among 100 mothers. The researcher found that there was a significant difference between the pre and post intervention level of anxiety at

The mothers anxiety reduced from three quarters of studied mothers to as low as one quarter of mothers which was very significant and emphasized the importance of education before labour and delivery.

In addition to Lauzon, L., Hodnett, E.D. (2014) conducted a specific program designed to teach women to recognize active labor in a view that it may be beneficial by potentially decreasing the incidence of early admission to hospital, increasing women's confidence, feelings of control and empowerment, and decreasing their anxiety in a study involving 245 women. The result was that the specific antenatal education program was associated with a reduction in the mean number of visits to the labor suite before the onset of labor majority of the mothers about three quarters This showed the effectiveness of prenatal classes for child birth preparation.

Conclusion

The current study findings succeeded in clarifying research hypothesis Primi parous women who receive video assisted teaching regarding normal labour have a lower level of anxiety than those who do not watch that video and receive routine care.

-Primi porous women who receive video assisted teaching regarding normal labour have a higher knowledge level than those who do not 


\section{Effect of Video Assisted Teaching Regarding Normal labour on Anxiety among Primi Parturient Mothers}

watch that video and receive routine care

There was a significant decrease in mean anxiety scores over time from pre intervention to post intervention .Although follow up mean anxiety scores was a little bit higher than post intervention.

After intervention, the majority of the studied PPM demonstrated that knowledge of stages of labour was high in control group and in study group but their knowledge of what to do in first stage was low in the control group than the study group.

There was no significant difference between control and study group regarding every item in knowledge of normal labour before intervention

Also their knowledge of what to do in second stage was very low in control group than in study group and the percentage of third stage knowledge was higher in the study group than control group.

\section{Recommendations}

In the light of current study findings the following can be recommended:-

- Video assisted teaching regarding normal labour should be a basic component of ante natal care programme for primi and multi parturient mothers at $\mathrm{MCH}$ centers.

- Health education that provided for pregnant woman should be supported by video tool to improve health status and reduce maternal and fetal complications.

- Nurses in MCH centers should give health education and psychological support for pregnant woman to maintain good maternal, newborn out-come.

Further research.
Further research is needed in rural and urban areas using a larger sample of primi parturient mothers:-

- This study needs to be replicated at other settings; also, it should be conducted on a larger number of samples.

- Different methods can be used to reduce anxiety and should be compared with video assisted teaching.

\section{Reference:}

Adams S, EberhardG, Eskild A. BJOG.(2012). Fear of childbirth and duration of labour: a study of 2206 women with intended vaginal delivery. [PubMed] [Google Scholar]

Aune I, MaritTorvik H, Selboe ST, et al (2015).Promoting a normal birth and a positive birth experience - Norwegian women's perspectives. Midwifery;31:721-7.

Boakye - Y A, (2015). Perceived stress and anxiety among Ghanaian pregnant women. Journal of Medical and Biomedical Sciences.; 4(2):29-37.21.

Brown, ST. (2015)Women's Evaluation of Intrapartum Nonpharmacological Pain Relief Methods Used during Labor . Journal of perinatal education advancing Normal birth. . [Cited 2010December 29];10(3): 1-8. Available from: URL: http:/ /www.ncbi.nlm.nih.gov/pmc//

Bryanton J, Beck CT. (2014) Postnatal parental education for optimizing infant general health and parentinfant relationships. Cochrane Database Syst Rev. :CD004068. [PubMed]

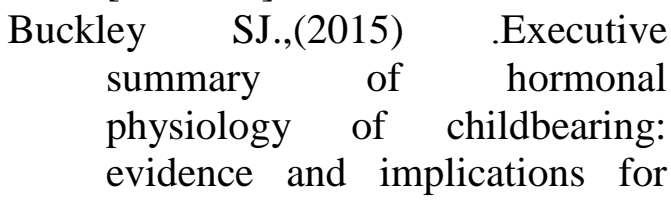




\section{Effect of Video Assisted Teaching Regarding Normal labour on Anxiety among Primi Parturient Mothers}

women, babies, and maternity care. J PerinatEduc;24:145-53.

.Crowe, K., et al (2009). Child birth fears. Midwifery. Retrieved from htpp://highbeam.com

El-Zanaty, F., Ann, A.,(2015).Egypt Demographic and Health Survey 2014.Calverton, Maryland: Ministry of Health and Population [Arab Republic of Egypt], El-Zanaty and Associates, and Macro International.

PMid:22464076http://dx.doi.org/10.10 16/j.ajog.2012.02.026

Fabian, H. M., et al. (2005). Childbirth and parenthood education classes. Obstetrics and gynecology of Scandinavia. 84(5), 436- 443. Retrieved from htpp://pubmed.gov.in.

Gagnon, A.J., \& Sandall, J. (2009). Individual or group antenatal education for childbirth or parenthood, or both. The Cochrane Database of Systematic Reviews. Retrieved from htpp://pubmed.gov.in

Hosseinasab D,Taghavis.,(2010). the effectiveness of prenatal education in decreasing child birth pain and anxiety:31:2430(Google scholar)

Lauzon,L.,Hodnett, (2014)Antenatal education for self-diagnosis of the onset of active labour at term. The
Cocrane Database of Systematic Reviews. Retrieved from http://pubmed.gov.in.

Nabb, M. T., et al (2016). A feasibility study to investigate a program of massage, controlled breathing and visualization, from 36 weeks of pregnancy until birth. Complementary therapy in clinical practice. 12(3), 222-231.

Sharma. S, et al. (2008). Effect of psycho-educational program related to labor and delivery. American Journal of Perinatology. Retrieved from htpp://pubmed.gov.in. 65.Shaw, (2003). Women's perceptions on their preparations for child

Shih, H. C. (2015). Effectiveness of the video-based Lamaze method on prenatal mothers' knowledge, attitudes, and practice. Times of Kaohsiung Military General Hospital. Retrieved from htpp://pubmed.gov.in.

Simon GE. (2014) Social and economic burden of mood disorders. Biol

Psychiatry.;54(3):208-15.

[PubMed: 12893097].

Soumya.SR, (2016) .effects of supportive education intervention package on pain and anxiety during labour among primi gravida mothers, International Journal of Applied Research (4): 259- 